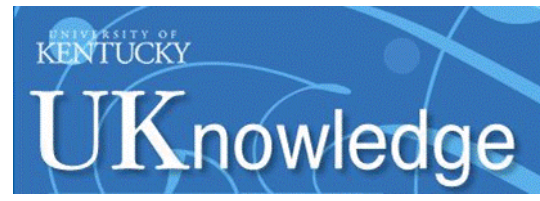

University of Kentucky

UKnowledge

\title{
$2-1-2018$
}

\section{Novel Fluconazole Derivatives with Promising Antifungal Activity}

Nishad Thamban Chandrika

University of Kentucky, nishad.tc@uky.edu

Sanjib K. Shrestha

University of Kentucky, sanjib.shrestha@uky.edu

Huy X. Ngo

University of Kentucky, huy.ngo@uky.edu

Kaitlind C. Howard

University of Kentucky, kaitlind.hydorn@uky.edu

See next page for additional authors

Right click to open a feedback form in a new tab to let us know how this document benefits you. Follow this and additional works at: https://uknowledge.uky.edu/ps_facpub

Part of the Medicinal-Pharmaceutical Chemistry Commons, and the Pharmacy and Pharmaceutical Sciences Commons 
Novel Fluconazole Derivatives with Promising Antifungal Activity

Digital Object Identifier (DOI)

https://doi.org/10.1016/j.bmc.2017.12.018

Notes/Citation Information

Published in Bioorganic \& Medicinal Chemistry, v. 26, issue 3, p. 573-580.

(c) 2017 Elsevier Ltd. All rights reserved.

This manuscript version is made available under the CC-BY-NC-ND 4.0 license

https://creativecommons.org/licenses/by-nc-nd/4.0/.

The document available for download is the author's post-peer-review final draft of the article.

Authors

Nishad Thamban Chandrika, Sanjib K. Shrestha, Huy X. Ngo, Kaitlind C. Howard, and Sylvie GarneauTsodikova 


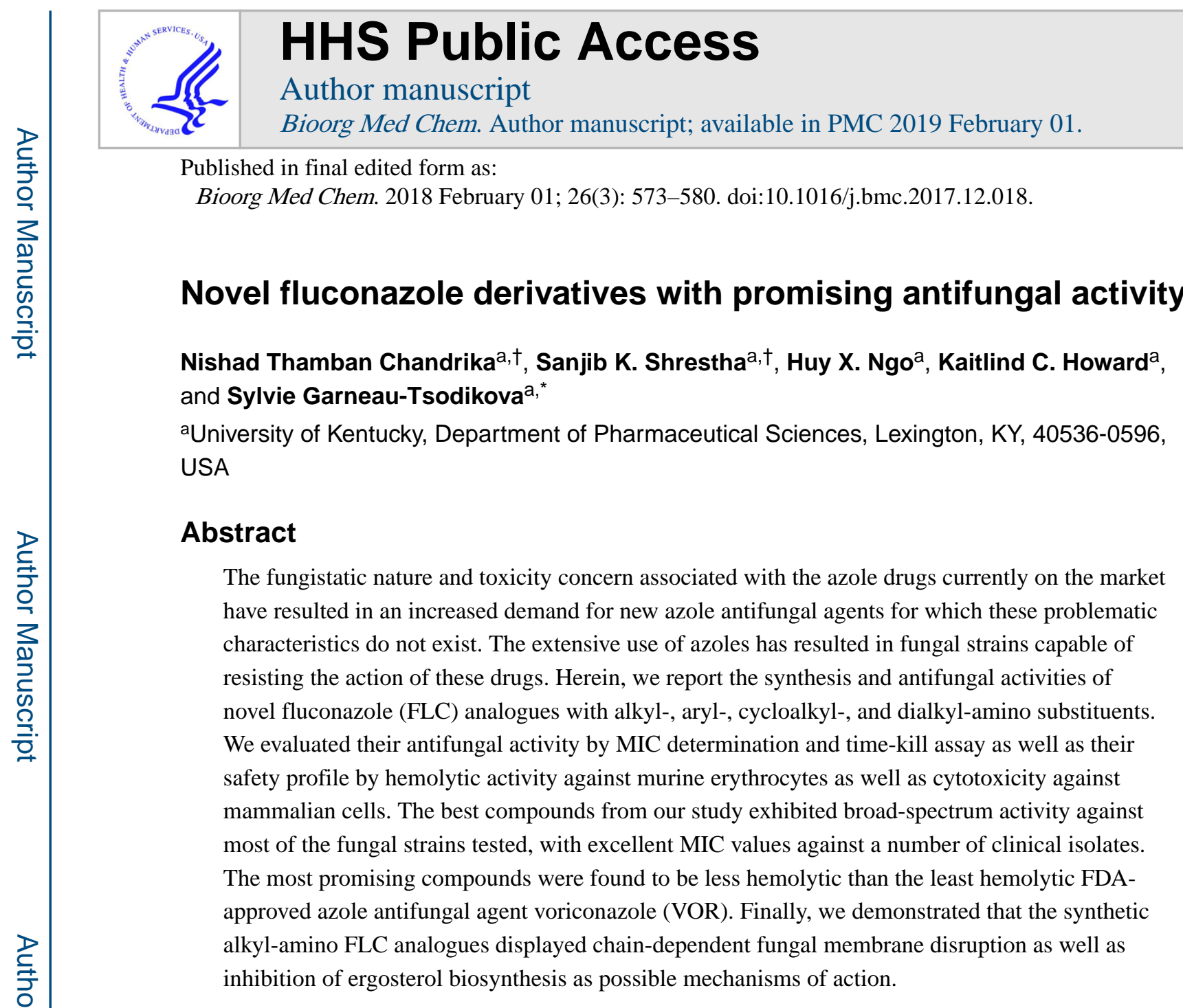

\section{TOC image}

\footnotetext{
*To whom the correspondence should be addressed: Sylvie Garneau-Tsodikova, sylviegtsodikova@uky.edu; Tel: 859-218-1686. $\uparrow$ These authors contributed equally to this work.

Publisher's Disclaimer: This is a PDF file of an unedited manuscript that has been accepted for publication. As a service to our customers we are providing this early version of the manuscript. The manuscript will undergo copyediting, typesetting, and review of the resulting proof before it is published in its final citable form. Please note that during the production process errors may be discovered which could affect the content, and all legal disclaimers that apply to the journal pertain.

Supporting Information Available: The supporting information includes experimental procedures for the chemistry and biological work performed. More specifically, it includes: (i) materials and instrumentation, (ii) protocols for the synthesis of compounds 1-16, (iii) a list of antifungal agents used, (iv) a list of organisms against which compounds 5-16 were tested along with their culture conditions, and experimental procedures for (v) MIC value determination, (vi) time-kill studies, (vii) hemolytic activity, (viii) in vitro cytotoxicity assay, (xi) membrane permeabilization assay, and (x) sterol profile by GC-MS. ${ }^{1} \mathrm{H}$ and ${ }^{13} \mathrm{C}$ NMR spectra (Fig. S1-S32) of all compounds generated in this study are also presented. The MIC values in $\mu \mathrm{M}$ are provided in Tables S1 and S2. The exact percentages with SDEV that were used to prepare Fig. 4 are provided in Table S3.

Author Contributions

N.T.C., S.K.S, and S.G.-T. design the study, analyzed the data, wrote the manuscript and supporting information, and made figures. N.T.C. and K.C.H. synthesized all compounds used in this study. H.X.N. performed the cytotoxicity assays and time-kill studies and generated Figs. 2 and 4. S.K.S. performed all other biochemical/biological experiments. N.T.C., S.K.S., H.X.N., and S.G.-T. reviewed the manuscript and supporting information. All authors approved the manuscript and supporting information.

The authors declare no conflict of interest.
} 

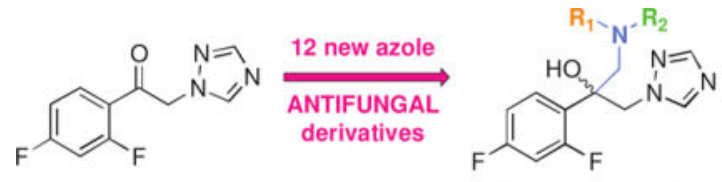

$\mathrm{R}_{1} / \mathrm{R}_{2}=$ alkyl or aryl

Less toxic/hemolytic

than FDA-approved azoles

Membrane disruptors

\section{Keywords}

Azoles; Clinical isolates; Cytotoxicity; Hemolysis; Time-kill studies

\section{Introduction}

The rise in the number of infections caused by fungi poses a serious threat to human health and life. ${ }^{1}$ Fungal infections can be endogenous (e.g., Candida infections) or acquired from the environment (e.g., Cryptococcus and Aspergillus infections). Invasive fungal infections have become a major problem for patients with immunodeficiency syndrome (e.g., AIDS), organ transplant patients, and patients receiving chemotherapeutic agents for cancer treatment. ${ }^{2-4}$ Clinically, candidiasis, aspergillosis, and cryptococcosis are the major infections in immunocompromised patients. ${ }^{5,} 6$ Candida and Aspergillus species are responsible for the majority of documented fungal infections. Recent studies indicated an epidemiological shift towards infections caused by emerging non-albicans Candida and Aspergillus species resistant to the current antifungal drugs. ${ }^{7-9}$ Non-albicans Candida species such as $C$. glabrata, $C$. parapsilosis, $C$. tropicalis, and $C$. krusei are more prominent now and they account for more incidence of invasive candidiasis such as candidemia than $C$. albicans. ${ }^{10-13}$ The relative presence of these fungal strains is region dependent. For example, C. glabrata is the second most common species after $C$. albicans in North America. ${ }^{14}$ Fungal strains such as $C$. parapsilosis and $C$. tropicalis are relatively more common in Europe, Australia, Latin America, and Asia. ${ }^{15-17}$ As resistance to the currently available antifungal agents is emerging in many of these non-albicans Candida, there is a need for developing novel antifungals. ${ }^{18}$

Most of the current drugs on the market are either highly toxic (e.g., amphotericin B (AmB)) or becoming ineffective due to appearance of resistant fungal strains (e.g., azoles such as fluconazole (FLC) and voriconazole (VOR)) (Fig. 1). ${ }^{19}$ Azoles are the most frequent class of antifungals used to treat fungal infections as they are inexpensive and are available for oral administration. ${ }^{20}$ However, there is an extensive documentation of intrinsic and developed resistance to azole drugs among $C$. albicans and non-albicans Candida species. As the frequency of occurrence of infections caused by non-albicans Candida species is increasing in clinical settings, there is currently a need to improve on the existing azole scaffolds to develop novel antifungals. Various studies were reported by our and other groups, which illustrated the role of alkylation on different drug scaffolds resulting in promising antifungal activity. ${ }^{21-27}$ There are examples of 2,4-difuoro-2-(1 H-1,2,4-triazo-1-yl)acetophenone analogues with linear $\mathrm{C}_{5}-\mathrm{C}_{8}$ alkyl chains ${ }^{25}$ and of an $n$-alkylated ebsulfur derivative with a linear $\mathrm{C}_{5}$ alkyl chain, which displayed strong antifungal activity. ${ }^{24}$ Similarly, examples of 
aminoglycosides (e.g., kanamycin B (KANB) and tobramycin (TOB)) with linear alkyl chains with 12 and 14 carbons $\left(\mathrm{C}_{12}\right.$ and $\left.\mathrm{C}_{14}\right)$ displaying antifungal activity were also reported. $^{21,22}$

Based on the information provided above and the promise shown by these small molecules, herein, we decided to generate novel FLC derivatives in which the triazole ring on the carbon alpha to the dihalophenyl ring of FLC was displaced by various linear alkyl-, aryl-, dialkyl-, and cycloalkyl-amino substituents. We report the synthesis of twelve novel FLC derivatives (Fig. 2) and their antifungal activity against a variety of $C$. albicans, non-albicans Candida, Aspergillus, and Cryptococcus strains as established by in vitro MIC determination as well as by time-kill studies. We explore the hemolytic activity as well as cytotoxicity of these compounds against murine erythrocytes and mammalian cell lines, respectively. Finally, we investigate the potential mechanism of action of selected compounds by probing their ability to disrupt fungal membrane.

\section{Results and discussion}

\subsection{Design and synthesis of antifungal agents 5-16}

We synthesized the alkyl-/aryl- and cycloalkyl-amino FLC derivatives 5-16 in two steps by using the commercially available fluorinated compound 2,4-difuoro-2-(1H-1,2,4-triazo-1yl)acetophenone as a starting material (Fig. 2B). We first converted the carbonyl group of 2,4-difuoro-2-(1H-1,2,4-triazo-1-yl)acetophenone to an epoxide by using trimethylsulfoxonium iodide in the presence of a strong base and a surfactant to yield the oxirane intermediate $\mathbf{4}$, which we then reacted with various amines (all commercially available, with the exception of amine $\mathbf{3}$ used in the synthesis of derivative 12) under mild basic conditions to afford derivatives 5-16. The amine $\mathbf{3}$ used for the synthesis of derivative 12 was prepared in three steps (Fig. 2A). The amino group of 6-aminohexanol was protected with Boc to yield compound $\mathbf{1}$, which was then subjected to nucleophilic substitution reaction with 1-iodopentane. The deprotection of the Boc group of intermediate 2 yielded the desired amine $\mathbf{3}$.

\subsection{Antifungal activity and structure-activity-relationship (SAR) analysis}

We first evaluated the antifungal activity of the newly prepared FLC derivatives 5-16 against a panel of seven C. albicans (ATCC 10231 (A), ATCC 64124(R) (B), ATCC MYA-2876(S) (C), ATCC 90819(R) (D), ATCC MYA-2310(S) (E), ATCC MYA-1237(R) (F), and ATCC MYA-1003(R) (G)), three non-albicans Candida (C. glabrata ATCC 2001 (H), C. krusei ATCC 6258 (I), and $C$. parapsilosis ATCC $22019(\mathbf{J})$ ), and three Aspergillus (A. flavus ATCC MYA-3631 (K), A. nidulans ATCC $38163(\mathbf{L})$, and A. terreus ATCC MYA-3633 (M)) strains using a concentration range of $0.03-31.3 \mu \mathrm{g} / \mathrm{mL}$ (Tables 1 and $\mathrm{S} 1$ ). We used the commercially available antifungal agents such as AmB, caspofungin (CAS), FLC, and VOR as positive controls for comparison. For derivatives 5-16 as well as the reference drugs AmB and CAS, we reported MIC-0 values, which correspond to no visible growth. We reported MIC-2 values (i.e., 50\% growth inhibition) for FLC and VOR against all fungal strains tested with the exception of strain A by VOR. We defined antifungal activity as excellent $(0.03-1.95 \mu \mathrm{g} / \mathrm{mL})$, good $(3.9 \mu \mathrm{g} / \mathrm{mL})$, moderate $(7.8-15.6 \mu \mathrm{g} / \mathrm{mL})$, or poor $(231.3 \mu \mathrm{g} / \mathrm{mL})$ 
based on MIC values. In this manuscript, we performed all activity comparisons by using the MIC values reported in $\mu \mathrm{g} / \mathrm{mL}$ (Note: the corresponding MIC values are also provided in $\mu \mathrm{M}$ into parentheses in Tables 1, 2, S1, and S2).

By a survey of the data reported in Table 1, the following observations could rapidly be made. The introduction of a side-chain comprising (i) a terminal hydroxyl group as in compound 11, (ii) a dialkyl-amino moiety as in derivatives 13 and 14, (iii) a cycloalkylamino group as in compound 15, and (iv) an aryl-amino functionality as in compound 16, resulted in all cases in molecules that were generally poor antifungals. A few exceptions were noted: compounds 14 and 15 displayed excellent $(0.975 \mu \mathrm{g} / \mathrm{mL})$ and good $(3.9 \mu \mathrm{g} / \mathrm{mL})$ activity against the $C$. parapsilosis strain $\mathbf{J}$. In contrary, we found that mono-alkylation resulted in much better antifungals. For derivatives 5-10, we generally observed better activity against non-albicans Candida and Aspergillus strains than against $C$. albicans. More specifically, when exploring the data for strains $\mathbf{H}-\mathbf{M}$, we found that compounds $\mathbf{7}$ and $\mathbf{8}$ displayed excellent (0.03-1.95 $\mu \mathrm{g} / \mathrm{mL})$ activity against the non-albicans Candida strains $\mathbf{H}, \mathbf{I}$, and $\mathbf{J}$, as well as against the Aspergillus strain $\mathbf{L}$. Additionally, both compounds $\mathbf{7}$ and $\mathbf{8}$ exhibited moderate $(7.8 \mu \mathrm{g} / \mathrm{mL})$ and good $(3.9 \mu \mathrm{g} / \mathrm{mL})$ activity against the Aspergillus strains $\mathbf{K}$ and $\mathbf{M}$, respectively. Compounds $\mathbf{5 , 6}, \mathbf{9}$, and 10, displayed excellent activity (0.06-1.95 $\mu \mathrm{g} / \mathrm{mL})$ against strains $\mathbf{J},(\mathbf{I}, \mathbf{J}$ and $\mathbf{L}),(\mathbf{H}$ and $\mathbf{J})$, and $(\mathbf{H}$ and $\mathbf{J})$, respectively. Compounds 5, 6, and $\mathbf{9}$ displayed moderate activity $(7.8-15.6 \mu \mathrm{g} / \mathrm{mL})$ against strains $(\mathbf{H}$ and $\mathbf{I}),(\mathbf{H}$ and $\mathbf{M})$, and $\mathbf{M}$, respectively. In addition, derivatives $\mathbf{9}$ and $\mathbf{1 0}$ showed good (3.9 $\mu \mathrm{g} / \mathrm{mL}$ ) activity against strains $\mathbf{I}$ and $\mathbf{L}$. When assessing the data for the $C$. albicans strains A-G, we found that compounds 6-9 exhibited excellent activity $(0.48-1.95 \mu \mathrm{g} / \mathrm{mL})$ against strain $\mathbf{A}$. We also observed that derivatives $\mathbf{7}$ and $\mathbf{8}$ generally displayed good to moderate (3.9-15.6 $\mu \mathrm{g} / \mathrm{mL}$ ) activity against strains $\mathbf{B}-\mathbf{G}$, with the exception of compound $\mathbf{8}$ displaying excellent $(1.95 \mu \mathrm{g} / \mathrm{mL})$ activity against strain $\mathbf{D}$. In addition, compounds $\mathbf{7}$ and $\mathbf{8}$ displayed excellent to good antifungal activity against most strains tested and derivative $\mathbf{9}$ displayed strong activity against non-albicans Candida and Aspergillus strains. These data indicated that the optimal chain lengths for maximal antifungal activity were $\mathrm{C}_{10}$ and $\mathrm{C}_{12}$, and the general trend for activity versus chain length was $\mathrm{C}_{10}>\mathrm{C}_{12}>\mathrm{C}_{8}>\mathrm{C}_{14}>\mathrm{C}_{16}=\mathrm{C}_{6}$. Finally, we observed that replacing one of the carbon atom in the side-chain by an oxygen as in compound $\mathbf{1 2}$ was detrimental as its activity against all strains was generally lower (higher MIC values) than that of its counterpart 8.

Having established that derivatives 5-16 displayed excellent antifungal activity against nonalbicans Candida strains, we further evaluated these compounds against three clinical strains of C. glabrata (CG1, CG2, and CG3) and C. parapsilosis (CP1, CP2, and CP3), as well as three Cryptococcus neoformans (CN1, CN2, and CN3) clinical isolates (Table 2). The trends observed in Table 2 correlated perfectly to those described for the data presented in Table 1. Compounds $\mathbf{1 1}$ and $\mathbf{1 3}$ were inactive against all nine clinical isolates tested, whereas compounds 14-16 exhibited excellent to good $(0.975-3.9 \mu \mathrm{g} / \mathrm{mL})$ activity against $C$. parapsilosis CP1, CP2, and CP3. For derivatives 5-10, we generally observed excellent activity against most $C$. glabrata, $C$. parapsilosis, and $C$. neoformans clinical isolates. More precisely, we found that compound $\mathbf{8}$ displayed excellent $(0.06-1.95 \mu \mathrm{g} / \mathrm{mL})$ activity against all clinical isolates tested. Compounds 7, 9, and 10 displayed excellent (0.03-1.95 $\mu \mathrm{g} / \mathrm{mL})$ 
activity against all isolates, with the exception of $C$. glabrata CG3. In addition, compound 6 displayed excellent $(0.12-1.95 \mu \mathrm{g} / \mathrm{mL})$ activity against CG2, CP1, CP2, CP3, and CN1, whereas compound 5 was found to display excellent $(0.975 \mu \mathrm{g} / \mathrm{mL})$ activity against $C$. parapsilosis CP1, CP2, and CP3 isolates. Overall, compounds 6-10 displayed better activity against the clinical isolates presented in Table 2 than they did against the commercially available strains for which the data are presented in Table 1. In general, we found that the three most active compounds synthesized (based on the data from Tables 1 and 2), 7-9, displayed better activity than FLC and similar or better activity than AmB against most of the fungal strains tested, as well as better activity than CAS against the three Aspergillus strains tested. When examining the data obtained with clinical isolates of $C$. glabrata, $C$. parapsilosis, and $C$. neoformans (Table 2), we observed that compounds 7-9 displayed similar or better activity than both CAS and FLC. When comparing compounds 7-9 to VOR, we found them to display stronger activity against some of the clinical strains tested.

The antifungals currently on the market are known to bind to proteins and be less efficient in intracellular matrices. For this reason, we tested the three best compounds, 7-9, against three representative strains, the $C$. albicans $\mathbf{A}$, the non-albicans Candida (C. parapsilosis) $\mathbf{J}$, and the Aspergillus $\mathbf{L}$, in presence and absence of fetal bovine serum (FBS) (Table 3). We found that the alkyl-amino azole analogue 7 retained its full antifungal activity (only 1 double dilution difference in some cases) against all three strains tested in the presence of FBS. Compound $\mathbf{8}$ retained its full activity against strain $\mathbf{J}$ and experienced a 2- and 4-fold decrease in activity in the presence of FBS against strains $\mathbf{A}$ and $\mathbf{L}$, respectively. Compound 9 displayed a 2- to 8-fold decrease in activity against the strains tested. Even though there was a small loss in activity in some instances, analogues 7-9 still remained good antifungal with the exception of compound $\mathbf{9}$ against strain $\mathbf{L}$.

\subsection{Time-kill studies}

The information regarding the rate and extend of fungicidal activity can be gathered by timekill assays. To determine the fungistatic or fungicidal nature of the compounds generated, we performed time-kill assays over a 24-h period with one of the best FLC derivatives, compound 7, and one of the good ones, compound 6. These compounds and VOR (positive control) were tested against fungal strains $C$. albicans ATCC 10231 (A) and C. parapsilosis ATCC 22019 (J) (Fig. 3). At 4× their respective MIC values, when tested against strain A, compounds $\mathbf{6}$ and $\mathbf{7}$ were found to be fungistatic and to be better than the control drug VOR. When tested against strain $\mathbf{J}$, both compounds also displayed fungistatic activity at up to $4 \times$ their MIC values. However, against strain $\mathbf{J}$, compound $\mathbf{6}$ displayed lower reduction in fungal growth than VOR, but compound $\mathbf{7}$ displayed activity equal to VOR. Overall, the compounds $\mathbf{6}$ and $\mathbf{7}$ performed better in time-kill studies than the control drug VOR.

\subsection{Hemolysis assay}

The promising antifungal activity shown by the synthetic analogues demanded further safety analysis for these compounds. We tested compounds 6-10 for their hemolytic activity against murine red blood cells (mRBCs) (Fig. 4 and Table S3). Compounds $6\left(\mathrm{C}_{8}\right)$ and $7\left(\mathrm{C}_{10}\right)$ displayed $<10 \%$ and $<40 \%$ hemolysis at concentrations of $31.3 \mu \mathrm{g} / \mathrm{mL}$ (1- to 512 -fold of its overall MIC values) and $15.6 \mu \mathrm{g} / \mathrm{mL}$ (1- to 512-fold of its overall MIC values), respectively. 
Similarly, compound $8\left(\mathrm{C}_{12}\right)$ induced only $21 \%$ lysis at $7.8 \mu \mathrm{g} / \mathrm{mL}$ (1- to 218 -fold of its overall MIC values). In addition, compounds $\mathbf{9}\left(\mathrm{C}_{14}\right)$ and $\mathbf{1 0}\left(\mathrm{C}_{16}\right)$ displayed $<50 \%$ and $<10 \%$ hemolysis at concentrations of $31.3 \mu \mathrm{g} / \mathrm{mL}$ (1- to 256 -fold of its overall MIC values) and $62.5 \mu \mathrm{g} / \mathrm{mL}$ (2- to 128 -fold of its overall MIC values), respectively. By comparing the hemolysis of compounds 6-10 with their corresponding MIC values against the non-albicans Candida, A. nidulans, and C. neoformans strains tested, we concluded that all of these compounds displayed minimal hemolytic activity. Overall, compounds $\mathbf{6}$ and $\mathbf{1 0}$ displayed the lowest hemolytic activity. Importantly, some of the newly synthesized compounds displayed less hemolytic effect than the FDA-approved control drug VOR.

\subsection{In vitro cytotoxicity assay}

Another crucial parameter to consider when developing antifungal drugs is their selectivity for fungal over mammalian cells. We tested our active compounds 6-10 against three different cell lines, HEK-293, BEAS-2B, and A549, along with the FDA-approved antifungal agent VOR as a positive control (Fig. 5). Against HEK-293, compounds 6, 7, and 10 exhibited no toxicity up to $31 \mu \mathrm{g} / \mathrm{mL}$ (1- to 512 -fold of its overall MIC values), 7.8 $\mu \mathrm{g} / \mathrm{mL}$ (1- to 256 -fold of its overall MIC values), and $7.8 \mu \mathrm{g} / \mathrm{mL}$ (1- to 16 -fold of its overall MIC values), respectively. However, compounds 8 and $\mathbf{9}$ exhibited some toxicity (>50\% cell survival) at a concentration of $3.9 \mu \mathrm{g} / \mathrm{mL}$ (1- to 64-fold of its overall MIC values) against HEK-293. Interestingly, compounds 8-10 were non-toxic to both BEAS-2B and A549 at up to $7.8 \mu \mathrm{g} / \mathrm{mL}$ (1- to 128 -fold of its overall MIC values). In the case of compound $\mathbf{6}$, no toxicity was observed against BEAS-2B (at $31 \mu \mathrm{g} / \mathrm{mL}$ ) (1- to 512-fold of its overall MIC values) and A549 (at $15.5 \mu \mathrm{g} / \mathrm{mL}$ ) (1- to 256-fold of its overall MIC values). With compound 10 we basically observed no toxicity against BEAS-2B and A549 at $7.8 \mu \mathrm{g} / \mathrm{mL}$ (1- to 16 -fold of its overall MIC values). A general trend of greater toxicity with respect to longer chain substitution was observed against the three cell lines. Compounds $\mathbf{6}$ and $\mathbf{7}$ exhibited better overall safety profiles than compounds 8-10. When considering the very low MIC values for these analogues against clinical isolates, these cytotoxicity data provide us with a reasonable therapeutic window.

\subsection{Membrane permeabilization assay}

Some amphiphilic molecules have been shown to cause membrane disruption and fungal cell death. Therefore, we decided to study the potential effect of compounds 8 and 9 with $\mathrm{C}_{12}$ and $\mathrm{C}_{14}$ linear alkyl chains to determine the impact of chain length on membrane disruption (Fig. 6). The control drug VOR and the KANB $\left(\mathrm{C}_{14}\right)$ derivative with a 14-carbon linear alkyl chain, were used as negative and positive controls, respectively. The propidium iodide (PI) dye was used as a probe as it can only enter cells with compromised membrane and bind to nucleic acid to emit fluorescence, which can be observed under a fluorescence microscope. At $4 \times \mathrm{MIC}$, the positive control KANB $\left(\mathrm{C}_{14}\right)$ significantly increased PI dye uptake by $C$. albicans ATCC 10231 (strain A), whereas the negative control VOR (at $4 \times$ MIC) did not allow for PI uptake by fungal cells. Compound 8 with a $\mathrm{C}_{12}$ linear alkyl chain (at $4 \times$ MIC) induced cellular uptake of PI dye into C. albicans ATCC 10231 (strain A), whereas compound 9 (with a $\mathrm{C}_{14}$ linear alkyl chain) did not cause cell membrane disruption. Interestingly, the chain length played a crucial role on membrane disruption of $C$. albicans

Bioorg Med Chem. Author manuscript; available in PMC 2019 February 01. 
ATCC 10231 (strain A), surprisingly with $\mathrm{C}_{12}$ being more membrane disrupting than $\mathrm{C}_{14}$. In order to completely understand the effect of chain length on membrane disruption, we additionally performed membrane permeabilization with compounds $\mathbf{5}, \mathbf{6}$, and $\mathbf{7}\left(\mathrm{C}_{6}-\mathrm{C}_{10}\right.$ linear alkyl chains) at $4 \times$ MIC. None of these compounds induced cellular uptake of the PI drug. From this study, we can conclude that one of the possible mechanisms of action for compound $\mathbf{8}$ is membrane disruption. Interestingly, any other linear chains beside the $\mathrm{C}_{12}$ displayed no membrane disruption.

\subsection{Sterol profile by GC-MS}

Since out of our compounds displaying antifungal activity only compound $\mathbf{8}$ caused membrane disruption of $C$. albicans ATCC 10231 (strain A) in the membrane permeabilization assay (section 2.6), we decided to explore by using gas chromatographymass spectrometry (GC-MS) the effect of compounds $\mathbf{8}$ and $\mathbf{9}$ on sterol composition during ergosterol biosynthesis (the mechanism of action of other conventional azoles) (Fig. 7). We evaluated the effect of the compounds $\mathbf{8}$ and $\mathbf{9}$ on sterol composition in C. albicans ATCC 10231 (strain A) at sub-MIC levels of $0.48 \mu \mathrm{g} / \mathrm{mL}$ (Fig. 7D) and $0.975 \mu \mathrm{g} / \mathrm{mL}$ (Fig. 7E), respectively. We also used VOR at $0.12 \mu \mathrm{g} / \mathrm{mL}$ and no drug control for comparison (Fig. 7B and 7A, respectively). In the absence of drug, strain $\mathbf{A}$ accumulated 100\% ergosterol (2), suggesting that the sterol biosynthesis was fully functional in this fungal strain. When treating strain A with VOR, we detected a lower amount of ergosterol $(\mathbf{2}, 50.80 \%)$, and an increased amount of lanosterol $(\mathbf{1}, 15.21 \%)$ and eburicol $\mathbf{( 3}, 1.73 \%)$. However, when strain $\mathbf{A}$ was treated with compound $\mathbf{8}$, we observed a relatively low amount of ergosterol (2, $36.62 \%)$ compared to VOR, but observed lower amounts of lanosterol $(\mathbf{1}, 10.03 \%)$, eburicol $(\mathbf{3}, 0.57 \%)$, and the fungistatic metabolite 14a-methyl ergosta-8,24(28)-diene-3 $\beta, 6 \alpha$-diol (4, 4.69\%) with respect to VOR. Interestingly, when strain A was treated with compound $\mathbf{9}$, we observed similar reduction in the amount of ergosterol $(2,36.43 \%)$ along with a related increase in lanosterol $(1,15.56 \%)$, eburicol $(3,1.16 \%)$ and the fungistatic metabolite $14 a-$ methyl ergosta-8,24(28)-diene-3 $\beta, 6 a$-diol $(\mathbf{4}, 15.56 \%)$. From these experiments, we can conclude that our compounds inhibit ergosterol biosynthesis similarly to the azole drug control VOR.

\section{Conclusions}

In summary, we have synthesized novel FLC derivatives in which the triazole ring on the carbon alpha to the dihalophenyl ring of FLC was displaced by various linear alkyl-, aryl-, dialkyl-, and cycloalkyl-amino substituents. We did not detect any antifungal activity with the aryl- and cycloalkyl-amino substituted FLC analogues. We observed that the antifungal activity of the alkyl-amino FLC derivatives depends on the length of the alkyl chains.

Compounds 6-9 were identified as promising antifungal agents with low hemolytic activity and low cytotoxicity. These analogues displayed great activity against some of the $C$. albicans, non-albicans Candida, and Aspergillus strains, and, in addition they were particularly excellent against the clinical strains of $C$. glabrata, $C$. parapsilosis, as well as $C$. neoformans tested. These compounds also exhibited superior activity against the clinical strains when compared to the control drugs CAS, FLC, and VOR. The possible mechanism of action for these FLC analogues was identified as membrane disruption with compound $\mathbf{8}$ 
with a $\mathrm{C}_{12}$ alkyl chain being more membrane disrupting than compound 9 with a $\mathrm{C}_{14}$ alkyl chain. Additionally, they were found to inhibit ergosterol biosynthesis. In the future, outside of the scope of this work, it will be interesting to see how these promising molecules will fair in the drug development process.

\title{
Supplementary Material
}

Refer to Web version on PubMed Central for supplementary material.

\section{Acknowledgments}

This work was supported by startup funds from the University of Kentucky (to S.G.-T.) and by NIH grant AI090048 (to S.G.-T.). H.X.N. was in part supported by a Pharmaceutical Sciences Excellence in Graduate Achievement Fellowship from the College of Pharmacy at the University of Kentucky.

\author{
Abbreviations \\ AmB amphotericin B \\ ATCC American Type Culture Collection \\ CAS caspofungin \\ CLSI Clinical and Laboratory Standards Institute \\ FBS fetal bovine serum \\ FLC fluconazole \\ KANB kanamycin B \\ mRBCs murine red blood cells \\ PI propidium iodide \\ SAR structure-activity-relationship \\ TOB tobramycin \\ VOR voriconazole
}

\section{References}

1. Garibotto FM, Garro AD, Masman MF, Rodriguez AM, Luiten PG, Raimondi M, Zacchino SA, Somlai C, Penke B, Enriz RD. New small-size peptides possessing antifungal activity. Bioorg Med Chem. 2010; 18:158-167. [PubMed: 19959366]

2. Beck-Sague C, Jarvis WR. Secular trends in the epidemiology of nosocomial fungal infections in the United States 1980-1990 National Nosocomial Infections Surveillance System. J Infect Dis. 1993; 167:1247-1251. [PubMed: 8486965]

3. Pfaller MA, Diekema DJ. Epidemiology of invasive candidiasis: a persistent public health problem. Clin Microbiol Rev. 2007; 20:133-163. [PubMed: 17223626]

4. Pannuti C, Gingrich R, Pfaller MA, Kao C, Wenzel RP. Nosocomial pneumonia in patients having bone marrow transplant Attributable mortality risk factors. Cancer. 1992; 69:2653-2662. [PubMed: 1315207] 
5. Latge JP. Aspergillus fumigatus and aspergillosis. Clin Microbiol Rev. 1999; 12:310-350. [PubMed: 10194462]

6. Steenbergen JN, Casadevall A. Prevalence of Cryptococcus neoformans var neoformans (Serotype D) Cryptococcus neoformans var grubii (Serotype A) isolates in New York City. J Clin Microbiol. 2000; 38:1974-1976. [PubMed: 10790132]

7. Groll AH, Walsh T. J Uncommon opportunistic fungi: new nosocomial threats. Clin Microbiol Infect. 2001; 7(Suppl 2):8-24.

8. Wald A, Leisenring W, van Burik JA, Bowden RA. Epidemiology of Aspergillus infections in a large cohort of patients undergoing bone marrow transplantation. J Infect Dis. 1997; 175:14591466. [PubMed: 9180187]

9. Viscoli C, Girmenia C, Marinus A, Collette L, Martino P, Vandercam B, Doyen C, Lebeau B, Spence D, Krcmery V, De Pauw B, Meunier F. Candidemia in cancer patients: a prospective multicenter surveillance study by the Invasive Fungal Infection Group (IFIG) of the European Organization for Research Treatment of Cancer (EORTC). Clin Infect Dis. 1999; 28:1071-1079. [PubMed: 10452637]

10. Miceli MH, Diaz JA, Lee SA. Emerging opportunistic yeast infections. Lancet Infect Dis. 2011; 11:142-151. [PubMed: 21272794]

11. Pfaller MA, Diekema DJ, Gibbs DL, Newell VA, Ellis D, Tullio V, Rodloff A, Fu W, Ling TA, Global Antifungal Surveillance, G. Results from the ARTEMIS DISK Global Antifungal Surveillance Study 1997 to 2007: a 105-year analysis of susceptibilities of Candida Species to fluconazole voriconazole as determined by CLSI standardized disk diffusion. J Clin Microbiol. 2010; 48:1366-1377. [PubMed: 20164282]

12. Puig-Asensio M, Peman J, Zaragoza R, Garnacho-Montero J, Martin-Mazuelos E, Cuenca-Estrella M, Almirante B, Prospective Population Study on Candidemia in Spain, P; Hospital Infection Study, G; Medical Mycology Study Group of the Spanish Society of Infectious, D; Clinical M, Spanish Network for Research in Infectious, D. Impact of therapeutic strategies on the prognosis of candidemia in the ICU. Crit Care Med. 2014; 42:1423-1432. [PubMed: 24557426]

13. Guo F, Yang Y, Kang Y, Zang B, Cui W, Qin B, Qin Y, Fang Q, Qin T, Jiang D, Li W, Gu Q, Zhao H, Liu D, Guan X, Li J, Ma X, Yu K, Chan D, Yan J, Tang Y, Liu W, Li R, Qiu H, China ST. Invasive candidiasis in intensive care units in China: a multicentre prospective observational study. J Antimicrob Chemother. 2013; 68:1660-1668. [PubMed: 23543609]

14. Pfaller MA, Diekema DJ. Epidemiology of invasive mycoses in North America. Crit Rev Microbiol. 2010; 36:1-53. [PubMed: 20088682]

15. Chen S, Slavin M, Nguyen Q, Marriott D, Playford EG, Ellis D, Sorrell T, Australian Candidemia, S. Active surveillance for candidemia Australia. Emerg Infect Dis. 2006; 12:1508-1516. [PubMed: 17176564]

16. Wang H, Xiao M, Chen SC, Kong F, Sun ZY, Liao K, Lu J, Shao HF, Yan Y, Fan H, Hu ZD, Chu YZ, Hu TS, Ni YX, Zou GL, Xu YC. In vitro susceptibilities of yeast species to fluconazole voriconazole as determined by the 2010 National China Hospital Invasive Fungal Surveillance Net (CHIF-NET) study. J Clin Microbiol. 2012; 50:3952-3959. [PubMed: 23035204]

17. Nucci M, Queiroz-Telles F, Tobon AM, Restrepo A, Colombo AL. Epidemiology of opportunistic fungal infections in Latin America. Clin Infect Dis. 2010; 51:561-570. [PubMed: 20658942]

18. Xiao M, Fan X, Chen SC, Wang H, Sun ZY, Liao K, Chen SL, Yan Y, Kang M, Hu ZD, Chu YZ, Hu TS, Ni YX, Zou GL, Kong F, Xu YC. Antifungal susceptibilities of Candida glabrata species complex Candida krusei Candida parapsilosis species complex Candida tropicalis causing invasive candidiasis in China: 3 year national surveillance. J Antimicrob Chemother. 2015; 70:802-810. [PubMed: 25473027]

19. Pore VS, Aher NG, Kumar M, Shukla PK. Design synthesis of fluconazole/bile acid conjugate using click reaction. Tetrahedron. 2006; 62:11178-11186.

20. Whaley SG, Berkow EL, Rybak JM, Nishimoto AT, Barker KS, Rogers PD. Azole antifungal resistance in Candida albicans and emerging non-albicans Candida species. Front Microbiol. 2016; 7:2173. [PubMed: 28127295] 
21. Shrestha SK, Fosso MY, Green KD, Garneau-Tsodikova S. Amphiphilic tobramycin analogues as antibacterial antifungal agents. Antimicrob Agents Chemother. 2015; 59:4861-4869. [PubMed: 26033722]

22. Fosso MY, Shrestha SK, Green KD, Garneau-Tsodikova S. Synthesis bioactivities of kanamycin Bderived cationic amphiphiles. J Med Chem. 2015; 58:9124-9132. [PubMed: 26592740]

23. Thamban Chandrika N, Shrestha SK, Ngo HX, Garneau-Tsodikova S. Synthesis investigation of novel benzimidazole derivatives as antifungal agents. Bioorg Med Chem. 2016; 24:3680-3686. [PubMed: 27301676]

24. Ngo HX, Shrestha SK, Garneau-Tsodikova S. Identification of ebsulfur analogues with broadspectrum antifungal activity. ChemMedChem. 2016; 11:1507-1516. [PubMed: 27334363]

25. Shrestha SK, Garzan A, Garneau-Tsodikova S. Novel alkylated azoles as potent antifungals. Eur J Med Chem. 2017; 133:309-318. [PubMed: 28395217]

26. Chang CW, Fosso M, Kawasaki Y, Shrestha S, Bensaci MF, Wang J, Evans CK, Takemoto JY. Antibacterial to antifungal conversion of neamine aminoglycosides through alkyl modification Strategy for reviving old drugs into agrofungicides. J Antibiot. 2010; 63:667-672. [PubMed: 20924381]

27. Shrestha S, Grilley M, Fosso MY, Chang CW, Takemoto JY. Membrane lipid-modulated mechanism of action non-cytotoxicity of novel fungicide aminoglycoside FG08. PLoS One. 2013; 8:e73843. [PubMed: 24040088] 

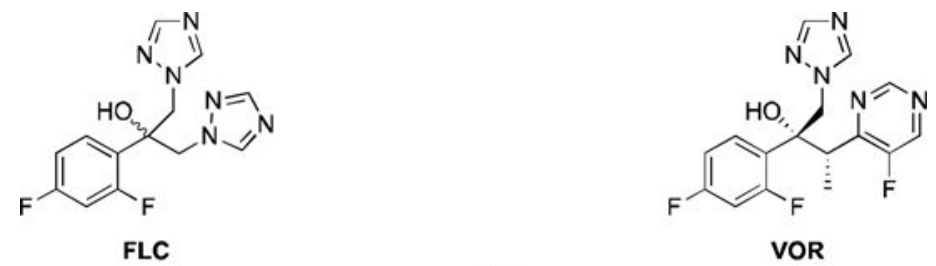

FLC

VOR
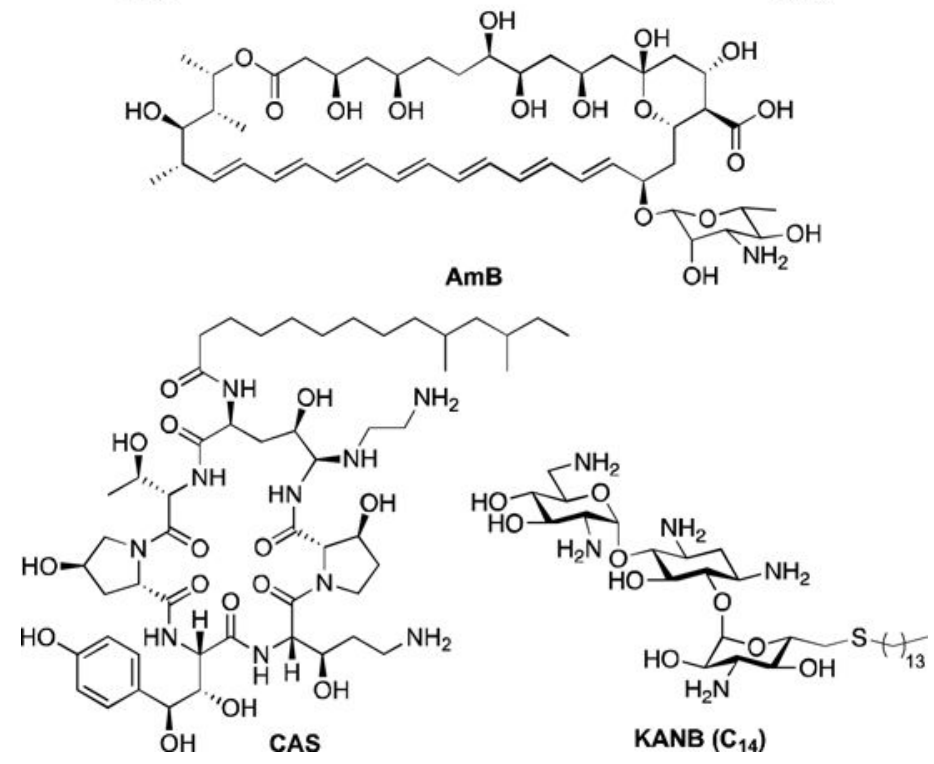

Fig. 1.

Structures of all antifungal agents used as controls in this study. 
A

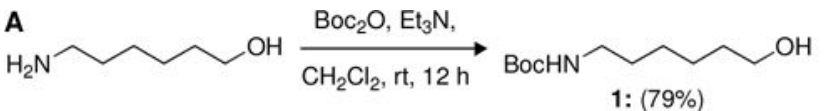

$x y^{\prime} \mathrm{NaH}, \mathrm{DMF}$,

${ }_{4} 0^{\circ} \mathrm{C}$ to rt, $24 \mathrm{~h}$

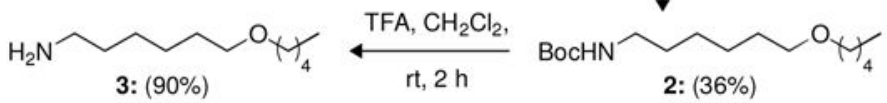

3: $(90 \%)$

trimethylsulfoxonium<smiles>O=C(Cn1cncn1)c1ccc(F)cc1F</smiles>

iodide, $\mathrm{NaOH}$,

cetyl bromide,

toluene, $60^{\circ} \mathrm{C}, 1 \mathrm{~h}$

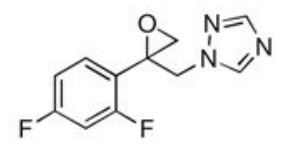

$\mathrm{CH}_{3}\left(\mathrm{CH}_{2}\right)_{n} \mathrm{NH}\left(\mathrm{CH}_{2}\right)_{n} \mathrm{CH}_{3}$, EtOH, $\mathrm{Et}_{3} \mathrm{~N}, 80^{\circ} \mathrm{C}, 12 \mathrm{~h}, \mathrm{n}=5$ and 7

cycloctyl amine, $\stackrel{\text { or }}{\mathrm{EtOH}}, \mathrm{Et}_{3} \mathrm{~N}$,

$80^{\circ} \mathrm{C}, 12 \mathrm{~h}$

4-isopropylaniline, $\mathrm{EtOH}, \mathrm{Et}_{3} \mathrm{~N}, 80^{\circ} \mathrm{C}, 12 \mathrm{~h}$

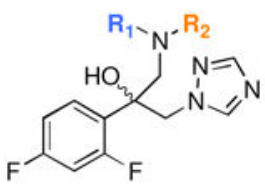

4: $(68 \%)$

13: $\mathrm{R}_{1}=\mathrm{R}_{2}=n$-hexyl $(57 \%)$

14: $\mathrm{R}_{1}=\mathrm{R}_{2}=n$-octyl $(65 \%)$

15: $R_{1}=$ cyclooctyl, $R_{2}=H(57 \%)$

16: $\mathrm{R}_{1}=p-\operatorname{PrPh}, \mathrm{R}_{2}=\mathrm{H}(57 \%)$

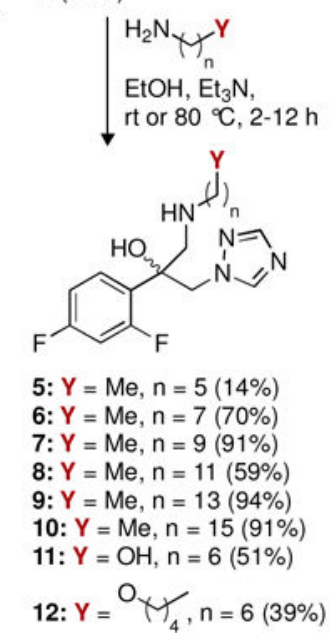

Fig. 2.

Synthetic schemes for the preparation of A. amine derivative 3, and B. novel azole analogues 5-16. 


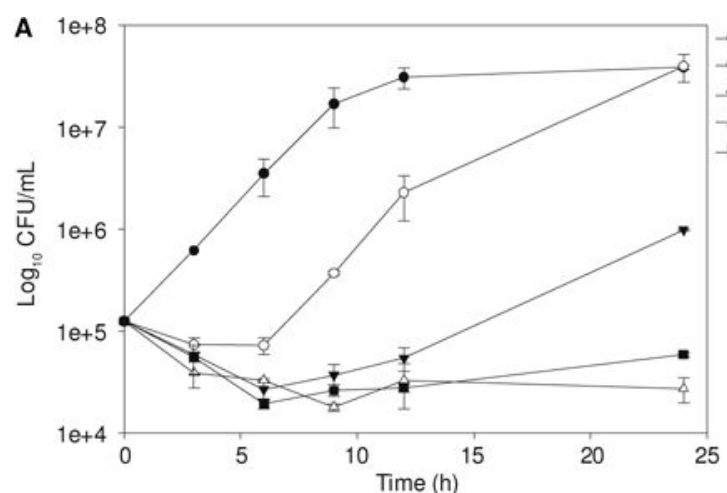

- No drug ctrl Cpd 6 (1x MIC)

$\checkmark$ Cpd 6 (2x MIC)

Cpd 6 (4x MIC)
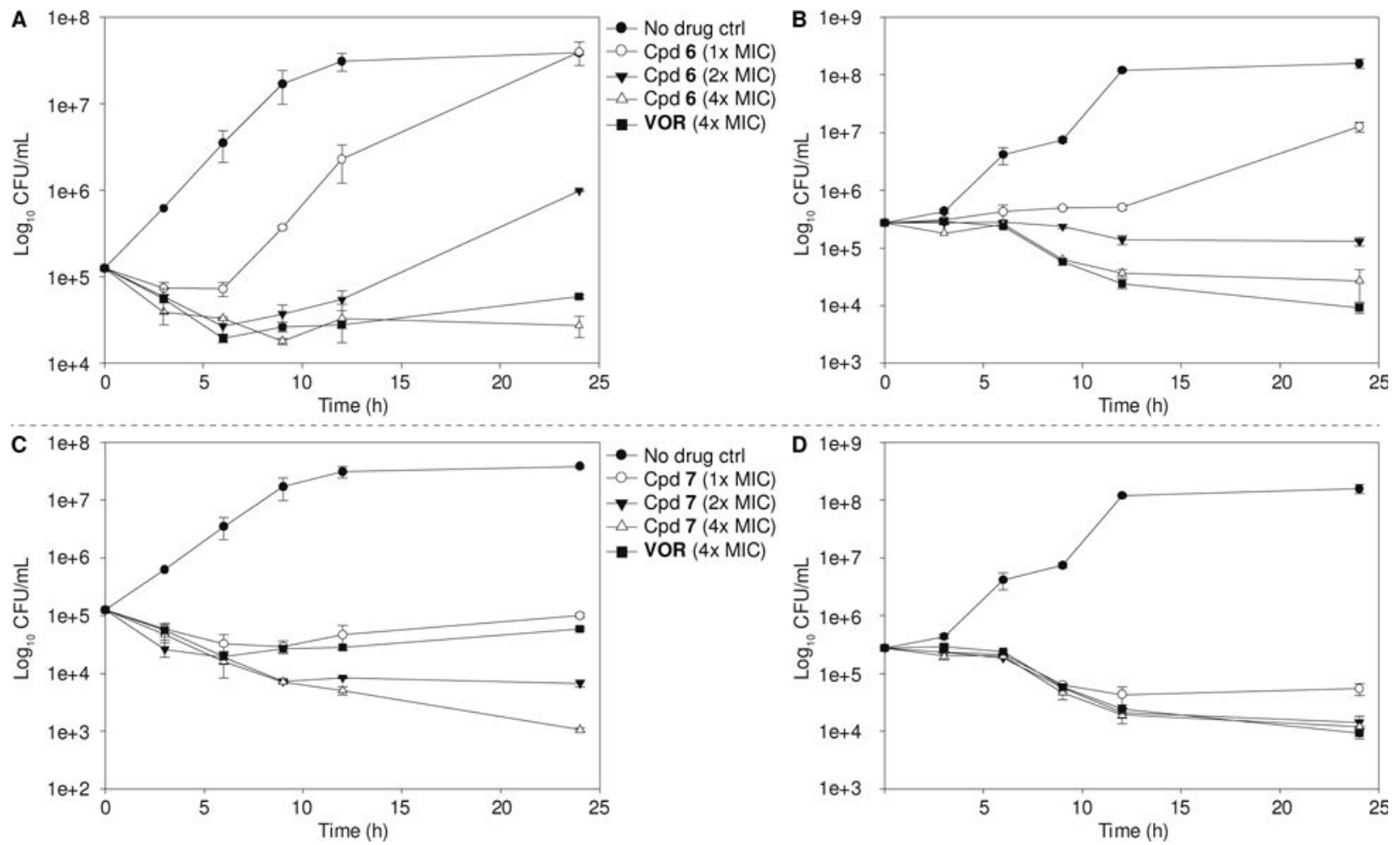

Fig. 3.

Representative time-kill curves for compounds $\mathbf{6}$ and $\mathbf{7}$ against $C$. albicans ATCC 10231 (strain A; panels A and C, respectively) and C. parapsilosis ATCC 22019 (strain J; panels B and $\mathbf{D}$, respectively). Fungal strains were treated with no drug (black circles), $1 \times$ MIC (white circles), $2 \times$ MIC (inverted black triangles), or $4 \times$ MIC (white triangles) of compounds 6 or 7, or with $4 \times$ MIC (black squares) of VOR. The experiments were performed in duplicate. 


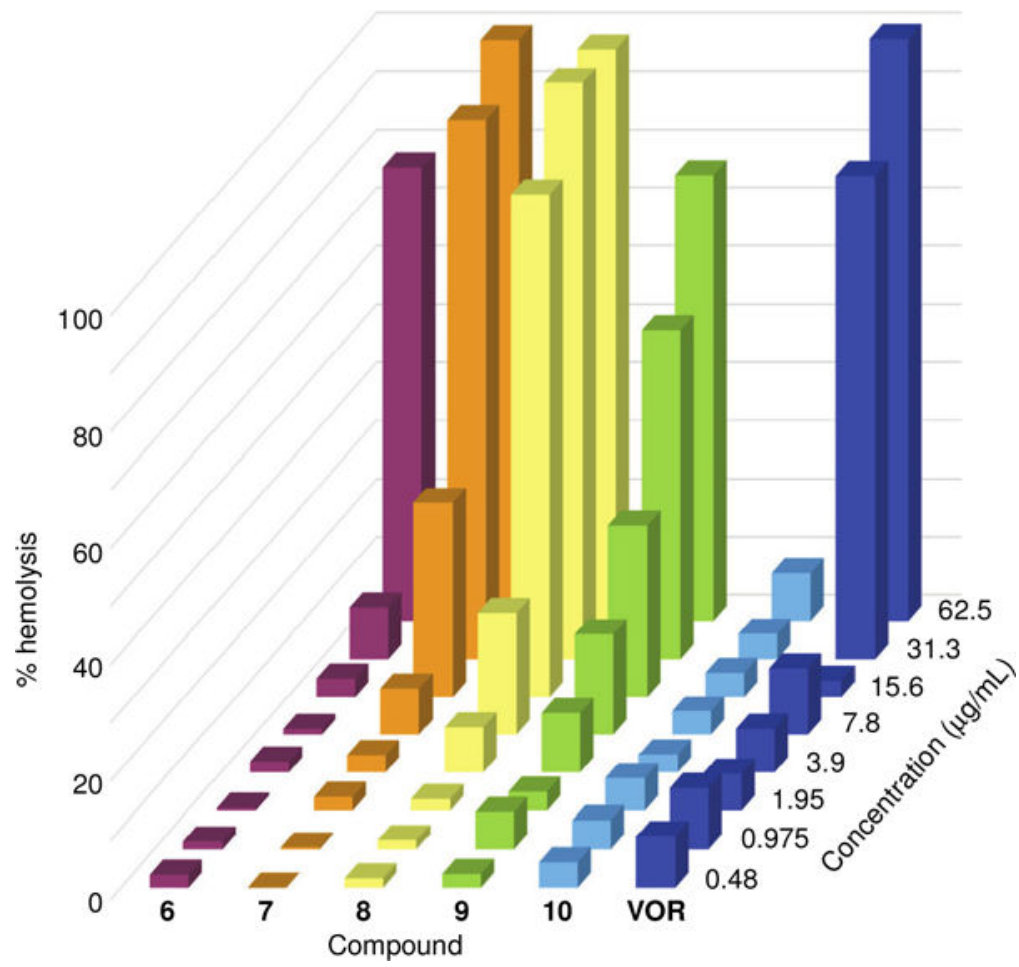

Fig. 4.

3D bar graph depicting the dose-dependent hemolytic activity of azole derivatives 6-10 and VOR against mRBCs, which were treated and incubated for $1 \mathrm{~h}$ at $37^{\circ} \mathrm{C}$ with each compound tested at concentrations ranging from $0.48-62.5 \mu \mathrm{g} / \mathrm{mL}$. Triton $\mathrm{X}-100 ®(1 \% \mathrm{v} / \mathrm{v})$ was used as a positive control (100\% hemolysis, not shown). 

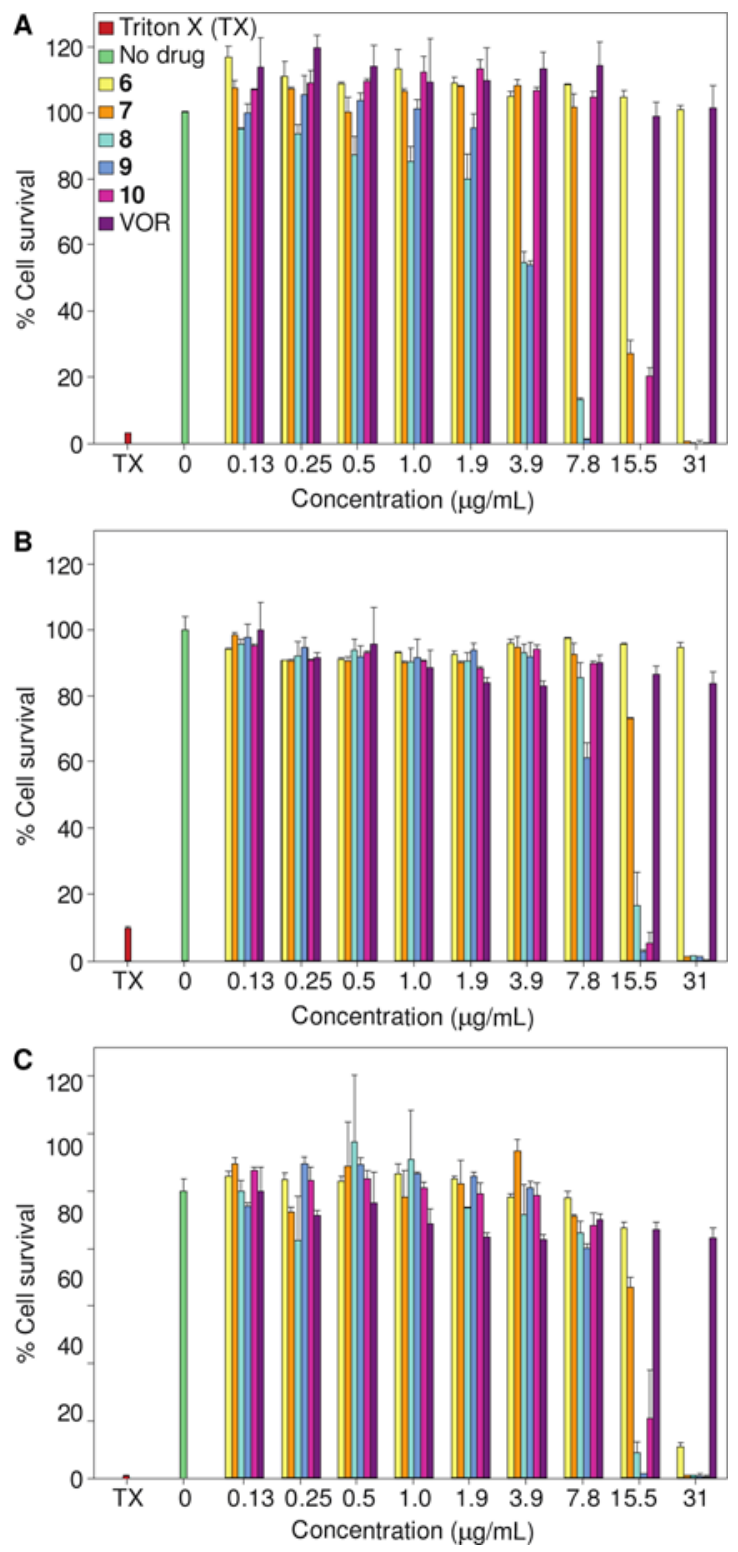

Fig. 5.

Representative cytotoxicity assays of compounds 6-10 against three mammalian cell lines: A. HEK-293, B. BEAS-2B, and C. A549. Cells were treated with various concentrations of compounds 6 (yellow), 7 (orange), 8 (turquoise), 9 (blue), 10 (pink), and VOR (purple). The positive control consisted of cells treated with Triton X-100® (TX, 20\% v/v, pink). The negative control consisted of cells treated with DMSO (no drug, green). The experiments were performed in duplicate. 

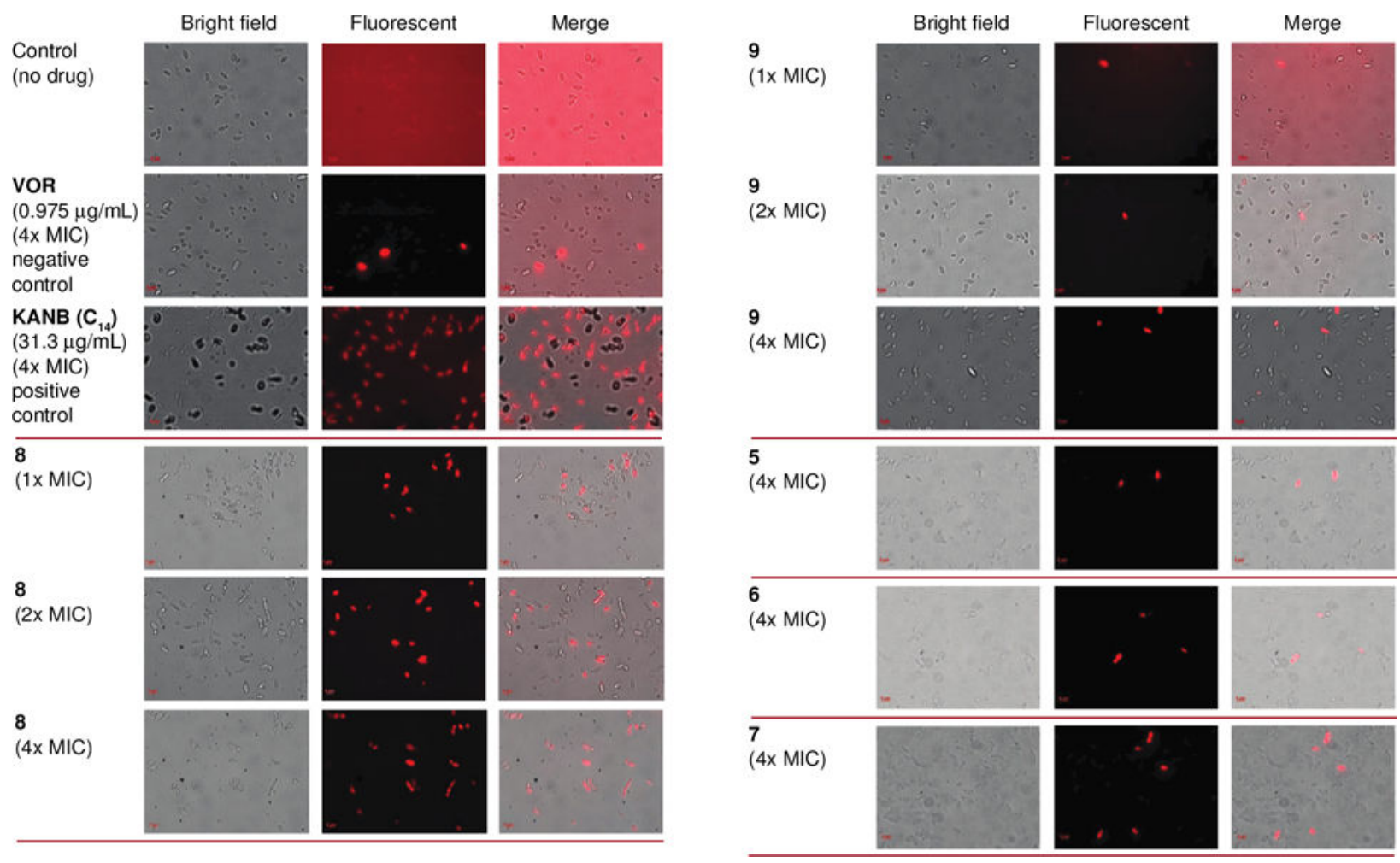

Fig. 6.

Effect of the controls VOR (negative) and KANB $\left(\mathrm{C}_{14}\right)$ (positive) as well as compounds 5-9 on the cell membrane integrity of $C$. albicans ATCC 10231 (strain A). For the three columns on the left from top to bottom: Propidium iodide (PI) dye uptake by yeast cells without drug, with VOR $(0.975 \mu \mathrm{g} / \mathrm{mL})$, KANB $\left(\mathrm{C}_{14}\right)(31.3 \mu \mathrm{g} / \mathrm{mL})$, and compound $\mathbf{8}(1 \times, 2 \times$, and $4 \times$ $\mathrm{MIC}$ ). For the three columns on the right from top to bottom: Propidium iodide (PI) dye uptake by yeast cells with compound $\mathbf{9}(1 \times, 2 \times$, and $4 \times$ MIC), as well as compound $\mathbf{5}, \mathbf{6}$, and 7 at $4 \times$ MIC. The experiments were performed in duplicate. 
A. Simplified ergosterol biosynthetic pathway and products resulting from inhibition of ERG11:
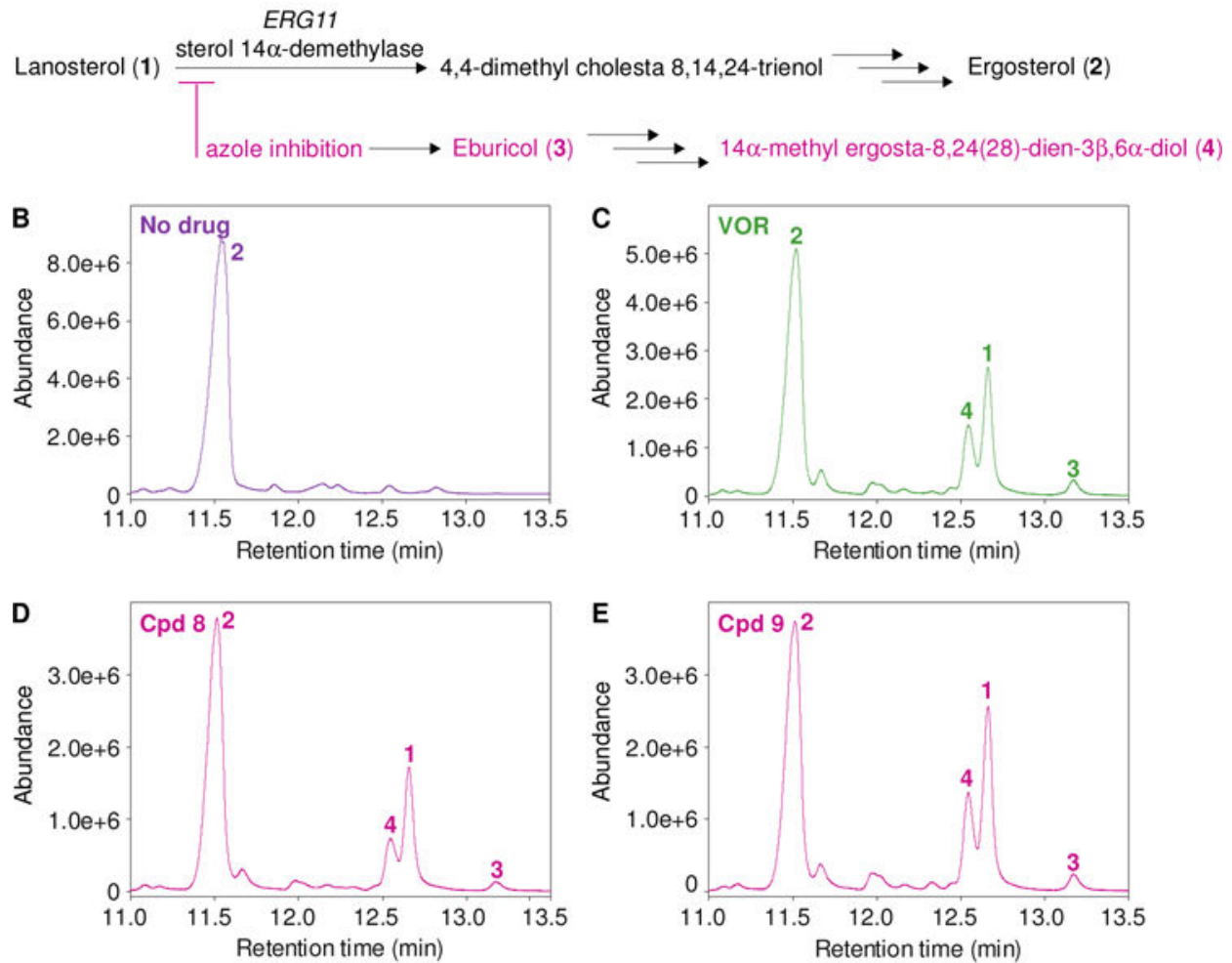

F. Sterol composition of untreated and VOR-, cpd 8-, and cpd 9-treated C. albicans ATCC 10231 (strain A):

\begin{tabular}{lllll}
\hline & \multicolumn{4}{c}{ Sterol composition (\%) } \\
\cline { 2 - 5 } Sterol & No drug & VOR & Cpd 8 & Cpd 9 \\
\hline Lanosterol (1) & ND & 15.21 & 10.03 & 15.56 \\
Ergosterol (2) & 100.00 & 50.80 & 36.62 & 36.43 \\
Eburicol (3) & ND & 1.73 & 0.57 & 1.16 \\
$14 \alpha$-methyl ergosta-8,24(28)-dien-3 $3,6 \alpha$-diol (4) & ND & 9.86 & 4.69 & 8.33 \\
\hline ND = not detected & & & &
\end{tabular}

Fig. 7.

A. A simplified ergosterol biosynthetic pathway and products resulting from inhibition of ERG11. B-E. GC-MS chromatograms of the sterols extracted from untreated and antifungal-treated $C$. albicans ATCC 10231 (strain A). The fungal strain treated with DMSO (no drug control, panel B), VOR at $0.12 \mu \mathrm{g} / \mathrm{mL}$ (panel C), compound 8 at $0.48 \mu \mathrm{g} / \mathrm{mL}$ (panel D), and compound 9 at $0.975 \mu \mathrm{g} / \mathrm{mL}$ (panel E). The peaks in these chromatograms are for lanosterol (1), ergosterol (2), eburicol (3), 14a-methyl ergosta-8,24(28)-dien-3 $\beta, 6 a-d i o l ~(4)$. F. A table summarizing the percentage of each sterol from panels B-E. 


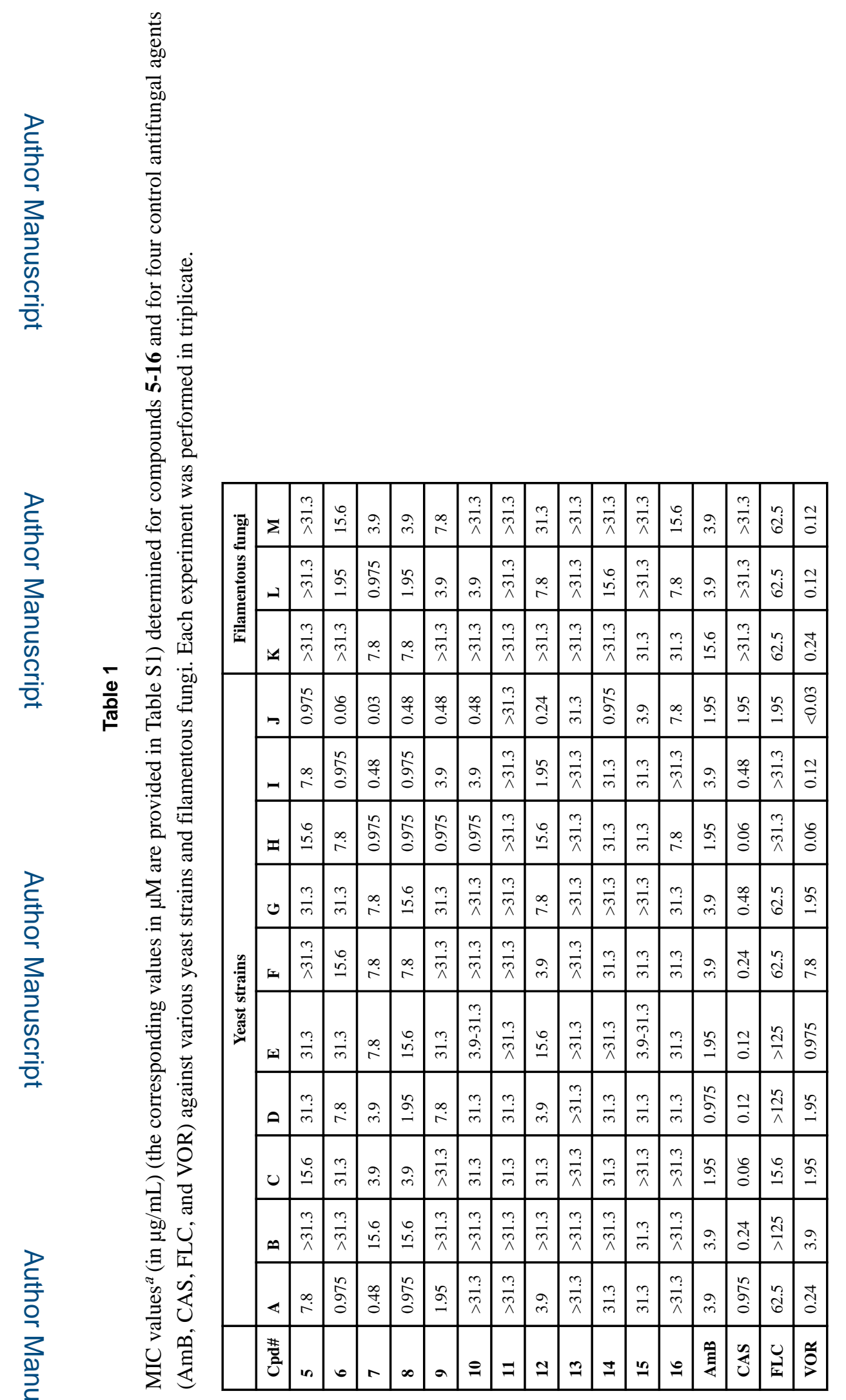

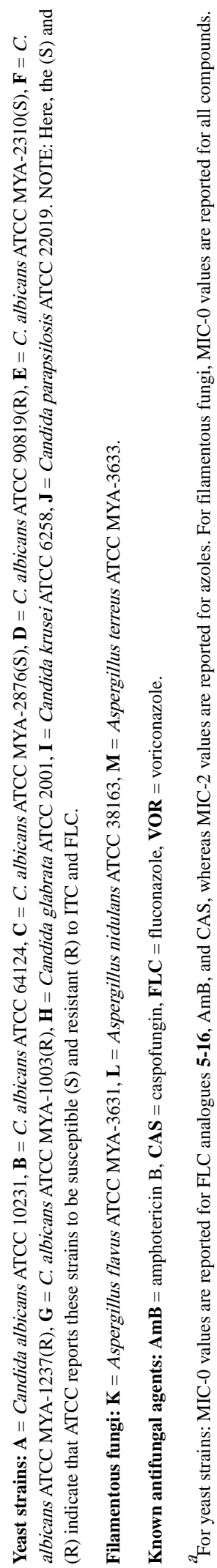

Bioorg Med Chem. Author manuscript; available in PMC 2019 February 01. 


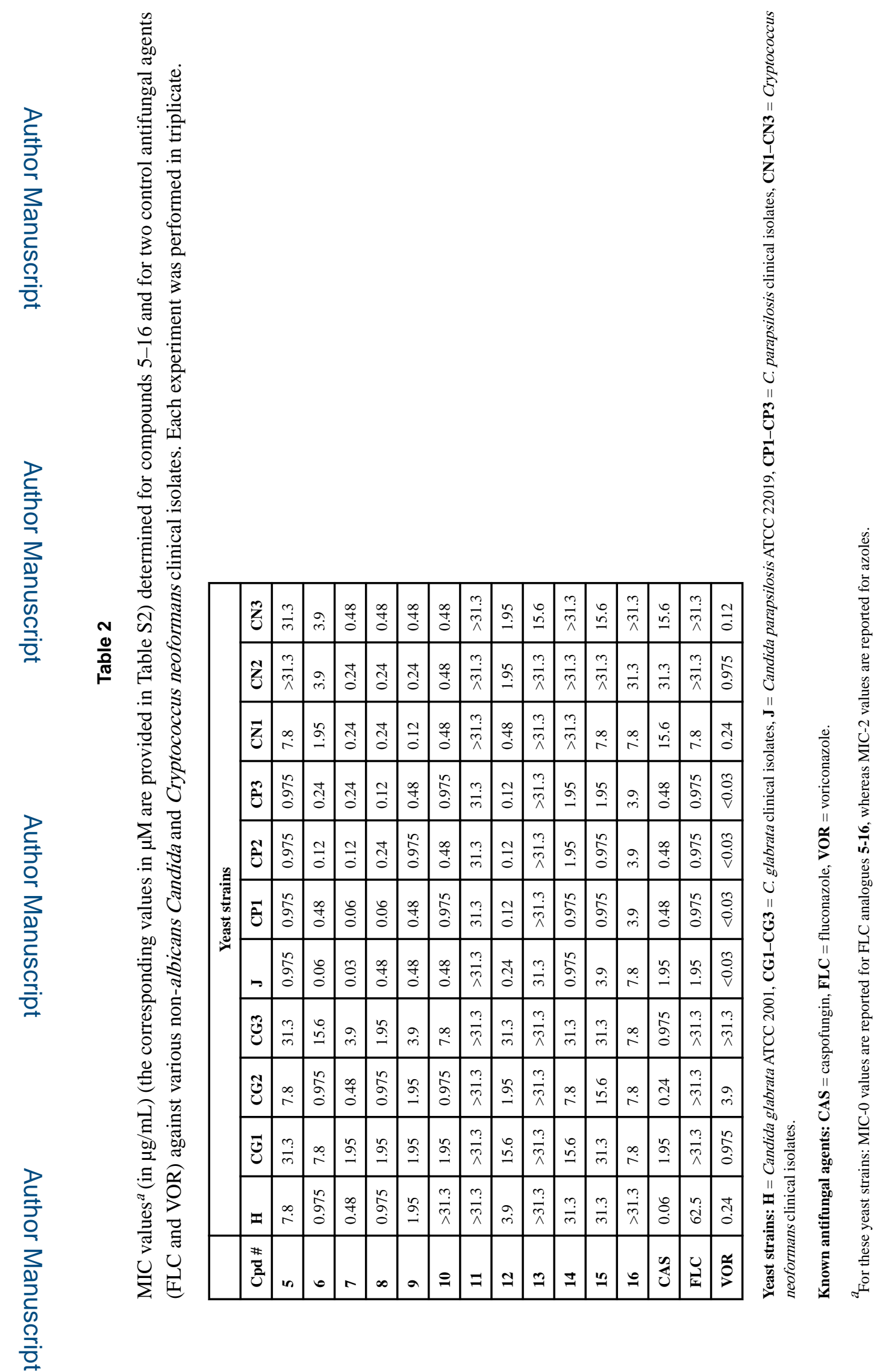

Bioorg Med Chem. Author manuscript; available in PMC 2019 February 01. 


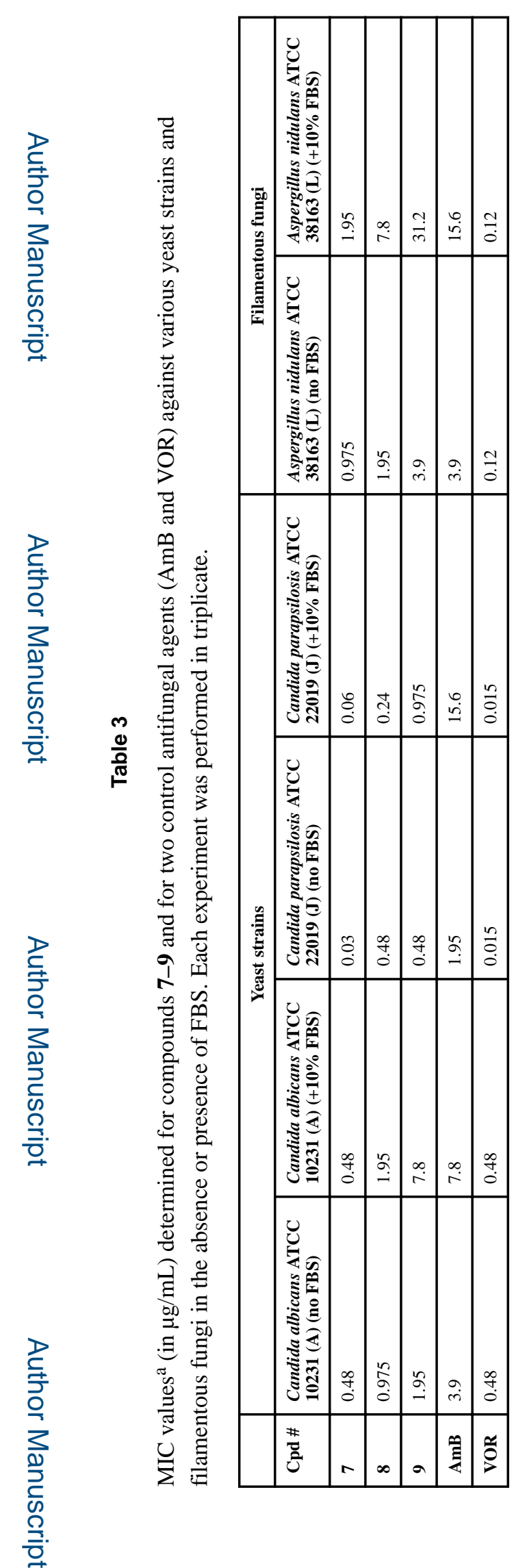

Bioorg Med Chem. Author manuscript; available in PMC 2019 February 01. 